\title{
A Participação Popular e o Direito à Saúde no Sistema Nacional de Saúde Brasileiro
}

\author{
PEOPLE'S PARTICIPA IION AND THE RIGHT TO HEALTH IN THE \\ BRAZILIAN NATIONAL HEALTH SYSTEM
}

Sueli Gandolfi Dallari ${ }^{(*)}$

\section{RESUMO}

Foram estudadas as conseqüências da evolução do conceito de saúde e verificou-se que a participação popular é elemento indispensável desse conceito. Buscou-se, então, compreender o papel desempenhado pela participação popular no sistema nacional de saúde e na definição do direito à saúde. Concluiu-se que existe a impossibilidade jurídica do direito à saúde sem a participação popular. Examinaram-se, em seguida, as condições para a garantia do direito à saúde no Brasil, tomando-se como exemplo o acesso ao medicamento e a proteção das pessoas que se submetem a pesquisas clínicas. Constatou-se que, apesar de contar com o arcabouço legal e administrativo, a participação popular para a garantia do direito à saúde no Brasil requer, ainda, um investimento importante na educação das pessoas e na divulgação científica e, particularmente, na formação dos operadores do direito em direito sanitário.

\section{Palavras-chave}

Democracia Direta; Políticas Públicas; Sistema Nacional de Saúde; Direito Sanitário.

\section{ABSTRACT}

The consequences of the health concept evolution have been studied and it was verified that popular participation is an indispensable element of

(") Coordenadora Científica, Núcleo de Pesquisas em Direito Sanitário da Universidade de São Paulo; Livre-Docente em Direito Sanitário, Universidade de São Paulo; Professora Titular, Faculdade de Saúde Pública da Universidade de São Paulo. E-mail:sdallari@usp.br. Recebido: 6.9.05. Aprovado: 17.10.05. 
this concept. One searched, then, to understand the role played by popular participation in the national health system and in the definition of the right to health. One concluded that there is legal impossibility for the right to health without popular participation. After that, the conditions for the guarantee of the right to health in Brazil has been examined, taking as example the access to medicines and the protection of the peciple who submit themselves to clinical research. It was evidenced that, althourh the legal and administrative structure are in place, popular participation for the guarantee of the right to health in Brazil still requires an important inves'ment in people's education and scientific spreading and, particularly, in the fo mation of law operators on Health Law.

\section{Key words}

Direct Democracy; Public Policies; National Health System; Health Law.

\section{A EVOLUÇÃO DO CONCEITO DE SAÚDE E SUAS IMPLICAÇÕES NA CARACTERIZAÇÃO DO DIREITO À SAÚDE}

É muito curioso - porque absolutamente desprezado - verificar a aproximação histórica da idéia de saúde daquela de exercício físico (ginástica) e dieta, isso porque a saúde não é originalmente um conceito científico, mas uma idéia comum, ao alcance de todos. Mesmo com a incorporação do sentido de cura e, portanto, com a formação da medicina, ainda a higiene alimentar e o exercício físico são caracterizados como importantes elementos de cura(1). Platão alarga um pouco mais a idéia de saúde acrescentando-lhe o campo da alma e a necessidade de que ele mantenha relação adequada com o corpo ${ }^{(2)}$. Assim, o estado de equilíbrio interno do homem e dele com a organização social e a natureza é sinônimo de saúde para a Antigüidade grega. Durante a Idade Média o saber culto continua a privilegiar o equilíbrio na definição de saúde ${ }^{(3)}$, tratados de ginástica e dietética são publicados como receitas de saúde para os não-médicos ${ }^{(4)}$, mas a reação coletiva à epidemia é a imagem mais marcante desse período. Assim aparecem os primeiros contornos da idéia de prevenção, implicando o respeito seja aos signos do zodíaco, seja ao desenrolar das estações, seja ao relacionamento adequado entre o clima e o corpo humano, mas, sobretudo, o afastamento dos contactos impuros - a melhor forma de prevenção.

(1) A medicina hipocrática é formada pela dietética ou ciência dos regimes e pela ginástica ou ciência dos exercícios.

(2) PLATÁO. A república, IV, 444b-c.

(3) Como ensina, por exemplo, Maimonides.

(4) RAUCH, A. Histoire de la santé. Paris: PUF, 1995. 
A evolução histórica mostra que o atual conceito de saúde pública começa a se delinear no Renascimento, correspondendo praticamente ao desenvolvimento do Estado Moderno. A assistência pública, envolvendo tanto a assistência social propriamente dita (fornecimento de alimentação e abrigo aos necessitados) como a assistência médica, era considerada matéria dependente da solidariedade de vizinhança, na qual o Estado deveria se envolver apenas se a ação das comunidades locais fosse insuficiente. Podese colocar nessa atuação subsidiária do Estado um primeiro germe do que viria a ser o serviço público de saúde. Por outro lado, a proteção da saúde é admitida no elenco das atividades do Estado liberal e recebe, portanto, um status constitucional. Isso significa que, apesar do empirismo que caracteriza a regulamentação das atividades de interesse para a proteção da saúde, as medidas de polícia administrativa relativas à tal proteção devem estar sob o manto da lei. Em suma, as atividades do Estado relacionadas à vigilância sanitária, durante a implantação do liberalismo, eram em tudo coincidentes com os interesses da burguesia vitoriosa: valorizando sobremaneira o individualismo dominante, limitá-lo apenas naquilo estritamente necessário à preservação da segurança individual, com o mais absoluto respeito à lei condição do Estado de Direito.

É apenas a partir da segunda metade do século XIX que a higiene se torna um saber social, que envolve toda a sociedade e faz da saúde pública uma prioridade política. São desse momento as primeiras tentativas de ligar a saúde à economia, reforçando a utilidade do investimento em saúde ${ }^{(5)}$. Por outro lado, inúmeros trabalhos de pesquisa, conformes ao paradigma científico vigente, revelam claramente a relação direta existente entre a saúde e as condições de vida. Assim, proteger a saúde das camadas mais pobres, modificar-lhes os hábitos de higiene, passa a ser um objetivo nacional, pois simultaneamente estar-se-ia lutando contra a miséria que ameaça a ordem pública. A idéia de prevenção encontra, então, ambiente propício à sua propagação. Tratava-se de encontrar os sinais precursores da doença para evitá-la. Nesse sentido, a vacinação e a descoberta de Pasteur, com o posterior isolamento do germe, provoca uma verdadeira revolução na prevenção de moléstias, pois proteger contra a infecção permite simplificar a precaução.

O início do século $X X$ encontra instaurada a proteção sanitária como política de governo. O Estado do bem-estar social reforça a lógica econômica, especialmente em decorrência da evidente interdependência entre as condiçōes de saúde e de trabalho, e se responsabiliza pela implementação da prevenção sanitária. Instituem-se, então, os sistemas de previdência social, que não șe limitam a cuidar dos doentes, mas organizam a prevenção sanitária. Inicialmente eles pressupunham uma diferenciação entre a assistência social - destinada às classes mais desfavorecidas e baseada no princípio

(5) Veja-se, por exemplo, o trabalho de CHADWICK, E. Reports on the sanitary condition of the laboring population of Great Britain. Edinburgh: University Press, 1965. 
de solidariedade e, portanto, financiada por fundos públicos estatais - e a previdência social, um mecanismo assecuratório restrito aos trabalhadores. Entretanto, exatamente porque a prevenção sanitária era um dos objetivos do desenvolvimento do Estado, logo se esclarece o conceito de seguridade social, que engloba os subsistemas de assistência, previdência e saúde públicas ${ }^{(6)}$. Trata-se, portanto, de identificar a responsabilidade a priori do Estado. Assim, mesmo no que respeita aos estilos de vida, verifica-se um grande investimento estatal(7).

Os últimos anos do século $X X$, contudo, revelam uma nova concepção da saúde pública, fortemente influenciada seja pelo relativo fracasso das políticas estatais de prevenção, que não conseguiram superar os limites impostos pela exclusão social, seja pela constatação - agora científica da importância decisiva de comportamentos individuais no estado de saúde. Por outro lado, o predomínio da ideologia neoliberal provocou uma diminuição do papel do Estado na sociedade em favor dos grupos e associações e da própria responsabilidade individual. A evolução da organização dos cuidados relativos à AIDS - na grande maioria dos Estados contemporâneos - é um exemplo eloqüente dessa nova concepção. Com efeito, prevaleceu a idéia de que a proteção contra a doença é responsabilidade individual e que os grupos - de doentes ou de portadores do vírus ou de familiares ou de amigos deles - devem organizar a prestação dos cuidados de saúde, ficando o Estado subsidiariamente responsável pelo controle da qualidade do sangue, fator importante na cadeia da causalidade, mas, certamente, não o único. Reforça-se, assim, o papel dos comportamentos individuais e não se questionam as estruturas econômicas e sociais subjacentes. De fato, o que se verifica, então, é que as estruturas estatais de prevenção sanitária passam a estabelecer suas prioridades, não mais em virtude dos dados epidemiológicos, mas, principalmente, em decorrência da análise econômica de custo/benefício. $E$ isso, por vezes, acaba implicando a ausência de prevenção, elemento historicamente essencial ao conceito de saúde pública.

Atualmente, a humanidade não hesita em afirmar - ainda que o matizando - que a saúde é um direito humano e que, como os demais direitos humanos, exige o envolvimento do Estado, ora para preservar as liberdades fundamentais, principalmente por meio da eficiente atuação do Poder Judiciário, ora para eliminar progressivamente as desigualdades, especialmente planejando e implementando políticas públicas ${ }^{(8)}$. Trata-se, então, da reivindicação do direito à saúde. Por outro lado, tendo o Estado assumido inicialmente a prestação de cuidados de saúde como prestaçãa, de um serviço público, grande quantidade de textos legais rege a sua $\epsilon$ "ecução.

(6) Modelo adotado, por exemplo, na Constituição Federal brasileira de 1988 (art.195).

(7) Considerem-se, por exemplo, os investimentos dos Estados contemporâneos na luta antitabagista.

(8) Veja-se, por exemplo: COMPARATO, F, K. Direitos humanos e Estado. In:FESTER, A. C. R. (Org.)

Direitos humanos e... São Paulo: Brasiliense,1989. p. 93-105. 
Isso porque, como se verá a seguir, toda atividade administrativa do Estado moderno é realizada sob a lei. Contudo, a saúde não tem apenas um aspecto individual, como já se viu, e não basta, portanto, que sejam colocados à disposição das pessoas todos os meios para a promoção, proteção ou recuperação da saúde para que o Estado responda satisfatoriamente à obrigação de garantir a saúde do povo. Hoje os Estados são, em sua maioria, forçados por disposição constitucional a proteger a saúde contra todos os perigos. Até mesmo contra a irresponsabilidade de seus próprios cidadãos. A saúde "pública" tem um caráter coletivo. O Estado contemporâneo controla o comportamento dos indivíduos no intuito de impedir-lhes qualquer ação nociva à saúde de todo o povo. E o faz por meio de leis. É a própria sociedade, por decorrência lógica, que define quais são esses comportamentos nocivos e determina que eles sejam evitados, que seja punido o infrator e qual a pena que deve ser-lhe aplicada. Tal atividade social é expressa em leis que a administração pública deve cumprir e fazer cumprir. São, também, textos legais que orientam a ação do Estado para a realização do desenvolvimento sócio-econômico e cultural. Conceitualmente, a sociedade define os rumos que devem ser seguidos para alcançá-lo, estabelecendo normas jurídicas cuja obediência é obrigatória para a administração pública(9). E como a saúde depende também desse nível de desenvolvimento, as disposições legais que the interessam estão contidas em tais planos de desenvolvimento do Estado.

\section{O SISTEMA NACIONAL DE SAÚDE E A PARTICIPAÇÃO POPULAR}

Em um rápido exame do sistema constitucional de proteção e promoção do direito à saúde no Brasil, verifica-se que a vontade de participação no governo, que fez do Brasil um Estado Democrático de Direito (CF, art. $1^{\circ}$ ), está presente na Constituição, examinada sob a ótica da saúde, como "democracia sanitária". De fato, a exigência de participação da comunidade foi erigida em princípio de organização do sistema público de saúde (SUS), assim como, em resposta à necessidade de racionalização, esse sistema deve ser organizado de acordo com a diretriz de descentralização, com direção única em cada esfera de governo; e de atendimento integral, com prioridade para as atividades preventivas (art. 198). Fruto dos mesmos movimentos que conquistaram o direito à participação direta no governo, a lei que organiza o sistema nacional de saúde, respeitando esses princípios constitucionais, foi editada em 1990. Refletindo a tensão entre as posições políticas representadas no Congresso Nacional, a Lei Orgânica da Saúde é, em

(9) É o que afirma o art. 174 da Constituição do Brasil, por exemplo: “... o Estado exercerá, na forma da lei, as funçōes de ... e planejamento, sendo este determinante para o setor público ...". 
realidade, duas leis: todas as disposiçōes sobre a participação popular e o financiamento, que constavam da primeira Lei Orgânica, a Lei Federal n. 8.080/90, foram objeto de um veto presidencial e um acordo foi negociado para a apresentação imediata de um novo projeto de lei regulando a matéria, cuja tramitação muito rápida (três meses no total) resultou na Lei Federal $n$. 8.142/90.

Especialmente três instituições caracterizam a democracia sanitária no Brasil: as conferências, os conselhos e os fundos de saúde. Deve-se notar que, em razão da adoção do modelo federal, essas instituições devem reproduzir-se nas três esferas de poder político do Estado. As conferências de saúde devem reunir-se pelo menos uma vez a cada quatro anos, para avaliar a situação de saúde e sugerir diretrizes para a formulação da política sanitária e devem ser convocadas pelo Poder Executivo (Lei Federal n. 8.142/ 90 , art. $\left.1^{\circ}, 1\right)$. Os conselhos de saúde são órgãos de caráter permanente $\mathrm{e}$ deliberativo, cujas decisões devem ser homologadas pelo Poder Executivo. Seu objetivo é formular estratégias e controlar a execução da política de saúde, inclusive em seus aspectos econômicos e financeiros (Lei Federal $n$. $8.142 / 90$, art. $\left.1^{\circ}, \mathrm{II}\right)$. Os fundos de saúde devem ser geridos por um Conselho, com a mesma representação paritária das demais intituiçōes [usuários (50\%) e de representantes do governo, dos prestadores de serviços e dos profissionais de saúde] e seu funcionamento deve ser supervisionado pelo respectivo conselho de saúde. Os recursos dos fundos de saúde devem ser alocados como despesa de manutenção e capital; investimento conforme a lei orçamentária; investimento conforme o Plano Quinqüenal; ou pagamento das açōes e serviços de saúde realizados por outras pessoas jurídicas (Lei Federal n. 8.142/90, art. $2^{\circ}$ ).

No plano legislativo é evidente, portanto, que os dispositivos constitucionais e a legislação ordinária organizaram mecanismos adequados para o exercício de uma verdadeira democracia sanitária. E, coisa curiosa caso se considere a tradição de governos ditatoriais convivendo com uma Constituição e um Poder Judiciário funcionando regularmente, no Brasil, todas as instituiçōes da democracia sanitária foram implementadas e atuam normalmente. Entretanto, a democracia sanitária encontrou uma sociedade que, depois da queda da ditadura e da conquista da Constituição, não mais se interessa com igual força pelos movimentos de ampliação da cidadania e um Estado não habituado a ter suas ações controladas. De fato, quando se considera a força dos movimentos em prol da participação popular por ocasião da Assembléia Constituinte, houve um expressivo enfraquecimento desses movimentos, por exemplo, quando se tratou do financiamento do sistema de saúde: a reforma do mecanismo de financiamento da saúde no sentido da real universalização desse direito aconteceu apenas no final do ano 2000. Tem-se claro, hoje, que os movimentos sociais são, sobretudo, reivindicativos e reticentes quanto à assunção de co-responsabilidade com os poderes públicos. Tal comportamento pode ser explicado, seja pela ne- 
cessária participação pessoal nas despesas, custos em horas de trabalho e mesmo nos meios de transporte, por exemplo, seja pela baixa capacidade de resposta do Estado às reivindicaçōes de seus dirigentes, o que constitui uma dificuldade para suas pretensōes políticas.

Por outro lado, quando se considera a operacionalização do federalismo de cooperação no campo da saúde, deve-se reconhecer que a democracia sanitária está inserida nos mecanismos da responsabilidade solidária da União, dos Estados e dos Municípios para "cuidar" da saúde. As relaçōes internas entre essas três esferas autônomas são regidas pelas Normas Operacionais Básicas (NOB) desde 1991. A primeira dessas normas (NOB 1/91) se limitava a aplicar o sistema de pagamento por produção de serviço ao setor público e a seguinte (NOB 1/92) vinculava a liberação de recursos à existência de um plano quinqüenal.

Foi a terceira Norma Operacional Básica (NOB 1/93) que criou os mecanismos de gestão participativos e descentralizados. Ela criou as comissōes entre gestores bi (gestores municipais e do Estado-membro) e tripartite (gestores dos Estados, dos Municípios e representantes do governo federal), encarregados de elaborar propostas para o sistema, acompanhar a implementação de normas e programas, avaliar os resultados e definir os critérios para a destinação de recursos. Ela criou, também, o mecanismo para a transferência direta dos recursos federais para os Municípios (fundo a fundo) e os modelos de autonomia progressiva, de adesão voluntária. Assim, se, por exemplo, um Município decide aderir à forma mais autônoma, esse Município tem a liberdade de decidir sobre a aplicação de certa quantidade de recursos transferidos em função do tamanho de sua população. Uma avaliação desses mecanismos de descentralização e democratização oriundos da ordem constitucional instaurada em 1988 mostrou que a forma engenhosa de repartir rendas e distribuir responsabilidades, adotada no seio dessas comissōes entre gestores, respeita verdadeiramente a autonomia federativa ${ }^{(10)}$.

A evolução das Normas Operacionais Básicas prosseguiu com a edição da NOB 1/96, que criou uma rubrica - PAB (Piso de Atenção Básica) especialmente para a atenção de base, além do sistema de pagamento por produção de serviço, e consagrou uma parte variável desse teto (PAB) aos programas federais (saúde da família, vigilância sanitária, assistência farmacêutica etc.). Assim, essa Norma Operacional Básica de 1996 limitou, em certa medida, a autonomia dos Estados e dos Municípios que, para receber mais recursos federais, devem adotar os programas federais. Finalmente, em 2001, foi editada a Norma Operacional de Assistencia à Saúde (NOAS 1/ 01) - publicada como Portaria Ministerial - que deixou aos gestores dos Estados a possibilidade de criar regiōes de saúde e de estimular a criação

(10) NASCIMENTO, P. R.; ZIONI, F. Relaçōes federativas no SUS: autonomia nas relaçōes intergovernamentais da CIB-SP. Revista de Direito Sanitário, São Paulo, ano 3, n. 2, p. 11-33, jul. 2002. 
de consortia entre os Municípios. Observe-se que essa norma, fruto da colaboração do Conselho Nacional de Secretários Estaduais de Saúde (CONASS), do Conselho Nacional de Secretários Municipais de Saúde (CONASEMS) e do governo foi aprovada na Comissão Intergestores Tripartite (CIT) e no Conselho Nacional de Saúde.

Verifica-se, portanto, que apesar de todas as dificuldades que decorrem da exigüidade do tempo de vida das instituições democráticas no Brasil e dos desafios postos pela falta de desenvolvimento social e econômico, a participação popular foi efetivamente introjetada no sistema sanitário nacional. Assim, em 2001, dentre mais de 5 mil municípios brasileiros, 99\% tinham um Conselho e o Fundo de Saúde e realizavam periodicamente uma Conferência de Saúde. Além disso, em vários Estados e Municípios - cujos governos eram mais democráticos - foram instituídos Conselhos Gestores junto aos serviços de saúde. E, também, a consulta pública faz parte do cotidiano da ANS e da ANVISA, autarquias formalmente definidas como "agências reguladoras"(11).

\section{A IMPOSSIBILIDADE JURIDICA DO DIREITO À SAÚDE SEM A PARTICIPAÇÃO POPULAR}

Tornar efetiva a garantia do direito à saúde, implica, portanto, compreender em toda sua extensão o conceito de saúde. Ora, contemporaneamente, tal compreensão só pode ser alcançada com a efetiva participação do povo na delimitação desse conceito. Com efeito, quando se conclui que a saúde inclui o controle dos riscos associados ao processo de produzir e consumir e que ela depende do estágio de desenvolvimento sócio-econômico e cultural de cada Estado, verifica-se que a complexidade dos interesses envolvidos exige a participação direta do povo para que o direito assim definido possa aproximar-se da idéia de justiça predominante em cada sociedade. Aliás, foi exatamente esse contexto de incertezas científicas e do risco da ocorrência de danos graves e irreversíveis, que induziu à formação do "princípio de precaução", cujo exame oferece um ótimo exemplo da essencialidade da participação popular na definição do direito contemporâneo. Revelando uma revalorização da busca dos verdadeiros responsáveis pelos comportamentos imprudentes, o princípio de precaução não se compraz apenas com a caracterização do dano a ser compensado. Ele abriga a conviç̧ão de que existem comportamentos que devem ser proibidos, sancionados e punidos. A mudança é, portanto, significativa: não basta determinar o montante da indenização, pois existem danos que não têm preço.

(11) Agência Nacional de Saúde Suplementar (criada pela Lei Federal n. 9.961/00) e Agência Nacional de Vigilância Sanitária (criada pela Lei Federal n. 9.782/99). 
Talvez a maior contribuição trazida pelo princípio da precaução seja, contudo, duplamente jurídica. Com efeito, ao deixar claro que se trata de analisar um risco, isto é, a possibilidade de causar dano a alguém, ainda que sem culpa, a exigência de precaução obriga a tomar em conta, seriamente, a instituição da perícia judicial, mas, também, extrajudicial. É conveniente observar que o risco está diretamente ligado à técnica, não ao indivíduo que dela se vale. A complexidade dos saberes envolvidos na decisão de instituir a vacinação generalizada contra uma grave infecção viral de incidência crescente, ou de retirar do mercado um produto suspeito de causar infecção e morte, com base apenas em informaçōes epidemiológicas ainda não comprovadas laboratorialmente, por exemplo, requer a participação de peritos que não devem ser responsáveis pela decisão, mas de quem se exige o domínio sobre sua área de especialidade e que deverão responder - social e juridicamente - pelas informaçōes prestadas. E, em caso de se exigir a resposta judicial, o juiz deverá ser capaz de formar seu convencimento a partir da apreciação de relatórios periciais que traduzam a complexidade da pesquisa científica em informações que sejam compreensíveis para todos os interessados. Verifica-se, portanto, a necessidade de investimentos tanto na formação dos pesquisadores, que deverão dominar, também, as ciências sociais - na teoria e na prática - para serem capazes de comunicar à sociedade os resultados de seus experimentos, quanto das pessoas em geral, que necessitam conhecer as bases do trabalho científico para poderem escolher o grau de risco ao qual consideram aceitável submeterem-se em nome do progresso.

A herança do Estado de Direito, criando um mecanismo engenhoso para garantir a supremacia da lei [um sistema dito "de freios e contrapesos", que reserva a edição dos atos gerais (normas abstratas que, no momento de serem emitidas, não se sabe a quem irão atingir) ao Legislativo, poder que, teoricamente, não dispõe de meios para cometer abusos; os atos especiais (atuaçōes concretas absolutamente limitadas pelos atos gerais) ao Executivo ${ }^{(12)}$, facilitou a mitificação do princípio da legalidade. A instauração do Estado Social de Direito, por sua vez, estimulou a proliferação de leis que atendem a interesses particulares e, também, de atos normativos da administração desvinculados de uma lei. Assim, o Judiciário contemporâneo vive uma situação, em certa maneira, esquizofrênica: tendo recebido a função de preservar a supremacia da lei na organização social, ele deve, agora, decidir qual a lei que deve prevalecer, entre as várias que dispōem sobre a mesma matéria de modos diferentes e algumas vezes opostos; ou, em muitas oportunidades, ignorar o dever de estrita observância da legalidade para convalidar ações da Administração tendentes à instauração de situação mais justa, não diretamente previstas em lei. E - necessário notar - justificando sempre sua

(12) Cf. DALLARI, Dalmo de Abreu. Elementos de teoria geral do Estado. 20. ed. São Paulo: Saraiva, 1999. p. 220. 
opção na perfeita submissão ao princípio da legalidade. A compreensão dessa inadequação do Poder Judiciário tal qual imaginado pelo gênio racionalista às exigências da atualidade, permite explicar a existência de decisões judiciais totalmente discrepantes em casos semelhantes e, igualmente, justificar o comportamento popular descrente da eficácia do recurso a esse Poder para a garantia de direitos. Por outro lado, a definição legal de padrōes de qualidade para as açōes e serviços de saúde não é da tradição brasileira. Com efeito, é muito freqüente que os gestores públicos, especialmente na área da saúde, não se preocupem com a forma legal de seus atos administrativos e, também, com a sua publicidade. Assim, soma-se à pouca legislação sobre o específico tema em questão, dificuldade de acesso àquela existente posta aos não especialistas. O juiz decide, então, baseado quase que exclusivamente na legislação trazida pelas partes ${ }^{(13)}$, o que reforça a necessidade de povo e gestores públicos procurarem dar forma legal à definição dos padrões de qualidade dos serviços e das ações de saúde.

\section{A GARANTIA DO DIREITO À SAÚDE NO BRASIL}

A construção formal do sistema de saúde brasileiro, como visto, respeitou totalmente os mandamentos constitucionais, tanto aqueles que se encontram previstos na seção saúde do capítulo reservado à seguridade social, como os que decorrem diretamente dos princípios e objetivos da Constituição em vigor. Desse modo, pode-se afirmar que o Brasil possui um sistema de saúde que permite e facilita a determinação do direito à saúde em coerência com as exigências da sociedade contemporânea. Por outro lado, tem-se verificado que os atos da Administração Sanitária, sejam eles normativos ou simplesmente materiais, vêm introduzindo a participação popular em seu cotidiano. Assim, também o Poder Executivo nacional tem fornecido os meios adequados para que o direito à saúde seja determinado de acordo com os requisitos postos pela sociedade do risco, característica do século XXI. Dois exemplos podem testemunhar a veracidade dessas afirmaçōes: os protocolos de tratamento e as pesquisas clínicas com seres humanos.

Os Protocolos Clínicos e Diretrizes Terapêuticas integram a política nacional de medicamentos, de responsabilidade do SUS, prevista na Lei Orgânica da Saúde (Lei Federal n. 8.080, art. 6ำ VI), constituindo elemento essencial da política de Estado para a saúde pública. Desde $1975^{(14)}$ a Organização Mundial da Saúde (OMS) vem insistindo na necessidade de os

(13) Veja-se, por exemplo a dissertação de mestrado de Silvia Badim Marques, "A relação do sistema jurídico e do sistema político na garantia do direito social à assistência farmacêutica: o caso do Estado de São Paulo", apresentada à Faculdade de Saúde Pública da Universidade de São Paulo em agosto de 2005.

(14) Resolução WHA 28.66, da 28ª Assembléia Mundial da Saúde. 
Estados formularem uma política que permita o acesso e favoreça o uso racional dos medicamentos por todas as pessoas, pois se verificou que 0 mercado mundial era composto, em grande parte (cerca de $70 \%$ ) por substâncias não essenciais, desnecessárias e até perigosas, e que um terço da população mundial não tem acesso a medicamentos essenciais ${ }^{(15)}$. Para a OMS, a formulação de uma política de medicamentos implica a definição de um conjunto de diretrizes com a finalidade de assegurar para toda a população uma provisão adequada de medicamentos seguros, eficazes e de boa qualidade e que sejam objeto de um uso racional. Tal política deve incluir, entre outros elementos, a produção, distribuição, legislação, registro, prescrição, dispensação, qualidade e propaganda comercial de medicamentos ${ }^{(16)}$.

No Brasil, em 1998, o Ministro da Saúde publicou a Portaria n. 3.916(17), contendo a Política Nacional de Medicamentos, baseada nas recomendações da OMS. Entre seus considerandos figura a informação de que houve um amplo processo de elaboração, "que envolveu consultas a diferentes segmentos direta e indiretamente envolvidos com o tema" e que a proposta da política foi aprovada pela Comissão Intergestores Tripartite e pelo ConseIho Nacional de Saúde. Ela contém um prefácio, informando sobre seu processo de elaboração; a introdução, vinculando-a aos princípios e diretrizes do SUS; uma justificativa, oferecendo as informações epidemiológicas; as diretrizes, conformes às recomendações da OMS; as prioridades, derivadas das diretrizes, dando as bases para seu alcance; as responsabilidades das esferas de governo no âmbito do SUS; como se dará seu acompanhamento e avaliação; e termina com a descrição da terminologia empregada.

São diretrizes da Política Nacional de Medicamentos, para facilitar aos mais carentes a obtenção dos medicamentos necessários e, além da otimização na distribuição, promover iniciativas que visem à redução dos preços de medicamentos. Para promover o uso racional do medicamento, além de todas as demais medidas contidas na própria Política Nacional de Medicamentos, deverá ser dada especial atenção à educaçãa de prescritores, dispensadores e consumidores, valorizando-se o receituário médico e a presença do farmacêutico na farmácia. Os Protocolos Clínicos e Diretrizes Terapêuticas configuram, igualmente, um importante instrumento para a promoção do uso racional e seguro do medicamento, eles "têm o objetivo de estabelecer claramente os critérios de diagnóstico de cada doença; o tratamento preconizado com medicamentos disponíveis nas respectivas doses corretas; os mecanismos de controle, acompanhamento e verificação de resultados; a racionalização da prescrição e do fornecimento de medicamentos; ... criar mecanismos para a garantia da prescrição segura e eficaz".

(15) SOBRAVIME O que é o uso racional de medicamentos. São Paulo: SOBRAVIME, 2001. p. 13.

(16) ORGANIZACIÓN Mundial de la Salud. Pautas para establecer politicas farmacéuticas nacionaneles. Ginebra: OMS, 1988.

(17) Publicada no DO n. 215-E, secção I, p. 18-22, de 10 de novembro de 1998. 
Os Protocolos Clínicos e Diretrizes Terapêuticas ${ }^{(18)}$ vêm sendo discutidos com os segmentos direta e indiretamente envolvidos com o tema. Para a elaboração dos primeiros de tais protocolos colaboraram, entre outros, a Organização Pan-Americana de Saúde (OPAS), diversas sociedades médicas, usuários do SUS e a própria indústria farmacêutica. Seu texto foi oferecido à consulta pública nacional por, pelo menos, 60 dias, período em que foram recebidas contribuições, que foram, em seguida, avaliadas e incorporadas ao texto final, "quando fundamentadas na literatura científica". Além disso, contrariando o costume vigente entre os gestores públicos na área da saúde, houve preocupação com a formalidade e a publicidade: os Protocolos Clínicos e Diretrizes Terapêuticas para cada um dos quadros clínicos assim avaliados foram publicados sob a forma de Portarias da Secretaria de Assistência à Saúde, no Diário Oficial da União.

Do mesmo modo, no que respeita à pesquisa clínica, a Lei Orgânica da Saúde acrescenta ao elenco das diretrizes estabelecidas constitucionalmente os princípios da "preservação da autonomia das pessoas na defesa de sua integridade física e moral" e, também, do "direito à informação sobre sua saúde". Ela determina, igualmente, que todas as esferas de poder político do sistema sanitário se responsabilizem pela "definição e controle dos padrões éticos para pesquisa", em articulação com entidades da sociedade (Lei $n$. 8.080, arts. $7^{\circ}$, III e V e 17, XVII). Assim, o Conselho Nacional de Saúde tem a base jurídica necessária para tratar da ética nas pesquisas de sua área. Especificamente tal atribuição foi esclarecida com a determinação - que the foi atribuída em seu decreto de organização - de "acompanhar o processo de desenvolvimento e incorporação científica e tecnológica na área da saúde visando à observação de padrōes éticos compatíveis com o desenvolvimento sociocultural do país" (Decreto Federal n. 99.438/90, art. 1, VII).

O Conselho Nacional de Saúde, resultado de um amplo processo de participação popular, que envolve todas as esferas de poder político no país e cujos mecanismos de ação têm sido, igualmente, permeados pela valorização da democracia direta, coordenou o processo de definição, construção e implementação do sistema brasileiro de análise ética das pesquisas que envolvem seres humanos. Uma comissão de representantes da comunidade científica, daqueles grupos que começavam a discutir a ética em pesquisa, dos usuários do sistema de saúde, da indústria e do governo definiu a metodologia de trabalho que permitiria apresentar o documento para a discussão e aprovação do Conselho. Tal metodologia envolveu a ampla divulgação dos documentos internacionais sobre o tema, a realização de seminários, consultas à comunidade e à Sociedade Brasileira de Bioética. Realizou-se, também, uma audiência pública para apreciar o documento preliminar, para

(18) Disponivel em: <http://dtr2001.saude.gov.br/sctie/portal_daf/protocolos_clinicos/arquivos_leitura/ 06_estrutura.pdf>. 
a qual foram especialmente convidadas as organizações mais diretamente ligadas ao tema. Enfim, pode-se afirmar, com segurança, que houve intensa participação popular no processo de definição e construção do sistema brasileiro de análise ética das pesquisas que envolvem seres humanos e que ela vem sendo mantida durante sua implementação, uma vez que todas as normas são publicadas como Resoluções do Conselho Nacional de Saúde. Garante-se, desse modo, além da participação da comunidade científica em sua elaboração, que tais normas sejam discutidas pelo maior órgão colegiado de participação popular na área da saúde.

Além disso, a atual estrutura para a análise ética dos protocolos de pesquisa que envolvem seres humanos, no Brasil, supõe a criação de Comitês de Ética em Pesquisa (CEP), instalados nas instituições que realizam esse tipo de pesquisa. Esse colegiado deverá contar em sua composição com profissionais da área de saúde, das ciências exatas, sociais e humanas e, pelo menos, um membro da sociedade representando os usuários da instituição, estando assegurado seu caráter multidisciplinar, também, por não serem mais de metade de seus membros profissionais do mesmo ofício. A norma em vigor sugere, igualmente, que se procure contemplar a participação de pessoas de sexos diferentes; que, na análise de pesquisas com grupos vulneráveis, sejam envolvidos especialistas, que funcionariam como membros ad hoc, e que pelo menos metade dos membros do CEP tenham experiência em pesquisa (Resolução n. 196/96, VII). E para estimular e regulamentar a criação de CEP's; para constituir um sistema nacional de informação e acompanhamento dos aspectos éticos das pesquisas envolvendo seres humanos; e, igualmente, para aprovar e acompanhar os protocolos de pesquisa em determinadas áreas temáticas, a estrutura para a análise ética dos protocolos de pesquisa que envolvem seres humanos, no Brasil, implica a Comissão Nacional de Ética em Pesquisa (CONEP), vinculada ao Conselho Nacional de Saúde. Ela é composta segundo critérios semelhantes àqueles que orientam a formação dos CEP's, sendo seus membros escolhidos pelo próprio Conselho Nacional de Saúde ou indicados por sorteio, a partir de listas elaboradas pelas instituições que integram o sistema (Resolução n. 196/96, VIII).

O sistema CEP's/CONEP foi concebido para assegurar que as pesquisas envolvendo seres humanos sejam realizadas com "o consentimento livre e esclarecido dos indivíduos-alvo" ... "a proteção dos grupos vulneráveis" ... "o máximo de benefícios e o mínimo de danos e riscos" ... , garantindo-se que os ... "danos previsíveis serão evitados" .... e que elas tenham ... "relevância social ... com igual consideração dos interesses envolvidos" (Resolução n. 196/96, III.1, a, b, c, d). Assim, a análise dos protocolos de pesquisa a ele submetidos deve verificar, especialmente, a existência do consentimento livre e esclarecido, devotando particular atenção à descrição dos procedimentos para o recrutamento das pessoas e sua real compreensão 
da justificativa, dos objetivos e dos métodos nela envolvidos. Esse exame exige, também, a verificação do cumprimento das fases anteriores do procedimento ou droga em teste, para que não reste dúvida - no atual estágio do conhecimento científico - sobre o mínimo de segurança e eficácia requeridos para, então, ponderar os eventuais benefícios em relação com os riscos e danos potenciais para as pessoas que se submeterem à pesquisa. Outro ponto importante, a ser especialmente avaliado pelo sistema brasileiro de análise ética dos protocolos de pesquisa que envolvem seres humanos, diz respeito à distribuição eqüitativa dos riscos e benefícios da pesquisa para as pessoas diretamente envolvidas, mas, igualmente, para a comunidade local e nacional (Resolução n. 196/96, VI).

Verifica-se, portanto, que o Brasil possui toda a estrutura formal que Ihe permite enfrentar o atual momento da história da humanidade, no que respeita ao uso racional do medicamento quanto ao controle social das pesquisas envolvendo seres humanos. De fato, a instauração do Estado Democrático de Direito, tanto na Constituição vigente como na legislação dela decorrente, permite que a normatização administrativa e a regulação ética resultem de um processo de radicalização da democracia. É formalmente possivel que as pessoas participem, possuindo todas as informações, das decisões que afetem o seu tratamento medicamentoso e a sua segurança, podendo, inclusive, reorientar o desenvolvimento científico ilimitado. A estrutura instalada permite, seja que se exerça a vigilância, tanto para preparar a decisão, quanto para acompanhar suas conseqüências, seja que se avaliem os impactos econômicos e sociais decorrentes da decisão de agir ou se abster. Essa estrutura para a elaboração dos Protocolos Clínicos e Diretrizes Terapêuticas e para a análise ética dos protocolos de pesquisa com seres humanos resulta, portanto, da compreensão de que os interesses envolvidos são sociais e que sua proteção pública deve ser determinada por um consenso político que estabeleça os limites entre a proteção pública, as escolhas individuais de prevenção ou de defesa, e as convenções sociais.

Para a garantia do direito à saúde não basta, entretanto, a existência de leis e de estruturas formais adequadas aos anseios sociais. Com efeito, sendo a saúde e o direito absolutamente dependentes da participação popular na atualidade, sem a direta participação das pessoas na definição desse direito não haverá garantia do direito à saúde. E necessário, portanto, que as pessoas possuam as informações necessárias para a compreensão dos interesses clínicos, econômicos e sociais envolvidos e, em conseqüência, dos riscos e benefícios decorrentes do processo de delimitação do direito à saúde para que possam realmente controlar o exercício desse direito. Assim, o investimento na formação de pesquisadores capazes de comunicar à sociedade os resultados de seus experimentos é também uma exigência ética, tanto quanto o investimento em divulgação científica, dando às pessoas o conhecimento sobre as bases do trabalho científico - seja nas ciências da saúde, seja na economia, no direito ou na política — pois tal conhecimento 
é indispensável para fundamentar a escolha dos limites do direito à saúde. Somente com a implementação de uma política pública de disseminação da informação será possível, em cada situação, analisar as repercussōes pessoais, sócio-econômicas e culturais do problema e estabelecer a correta relação custo/benefício, indispensável à adequada e eficaz definição do direito à saúde.

Para a garantia do direito à saúde não basta, também, acrescentar à existência de leis e de estruturas formais adequadas aos anseios sociais a existência de pessoas amplamente informadas. O funcionamento ideal do sistema jurídico-sanitário, precisa, igualmente, de operadores que "falem a língua do sistema sanitário"(19). Assim, seria interessante que os órgãos envolvidos - Polícia, Ministério Público e Magistratura - se organizassem para oferecer a infra-estrutura de apoio necessária para a apresentação dos argumentos e a formação do convencimento, respectivamente, em matéria de direito sanitário. Isso deve implicar, por exemplo, a existência de facilidades para o acesso (virtual ou real) à legislação e à doutrina especializada no assunto e, igualmente, o oferecimento de cursos e seminários sobre temas de direito sanitário. É indispensável, porém, que todos - juízes, membros do Ministério Público e policiais - tenham acesso a tais recursos de infra-estrutura em qualquer Comarca onde se encontrem, uma vez que questōes de segurança sanitária envolvem pessoas em todas as partes do território brasileiro e não apenas nos grandes centros urbanos.

Para a garantia do direito à saúde todas essas condições são necessárias; porém, não são suficientes. Sem o efetivo exercício da cidadania não há garantia do direito à saúde. De fato, tanto para que a lei reflita o ideal de justiça da sociedade, quanto para que os órgãos da Administração Sanitária normatizem as relações concretas que podem ameaçar a saúde ou para que o Poder Judiciário decida sempre preservando o direito à saúde, é indispensável a participação dos cidadãos, atuando sua parcela de responsabilidade na autoridade deliberativa e judiciária da polis. Assim, é necessário que as condições procedimentais do processo democrático sejam protegidas ${ }^{(20)}$. Ou seja, torna-se necessário preservar o papel dos Parlamentos como legítimos representantes dos interesses dos diferentes setores envolvidos tanto no processo de produzir, consumir e controlar os riscos sanitários quanto na definição das políticas públicas de assistência à saúde, combinando-o com a extensão das hipóteses de participação dos cidadãos junto aos serviços de saúde, com o controle democrático dos meios de comunicação de massa, especialmente no que se refere diretamente aos riscos sanitários, e com o fortalecimento de comissōes especializadas no tema nas estruturas partidárias. É necessário, pois, que povo e governantes se unam na construção e

(19) Adaptando-se a expressão de Teubner, quando discute a regulação da sociedade pelo direito reflexivo. (TEUBNER, G. Le droit. um système autopoiëtique. Paris: PUF, 1993).

(20) Na lição de HABERMAS, J. Droit et démocratie: entre faits et normes. Paris: Gallimar, 1996. 
manutenção dos espaços públicos de discussão e que seja feito um esforço importante em educação, seja ela especializada em direito sanitário para os operadores do direito, seja - não menos importante - sobre os métodos da ciência para todo o povo. Apenas assim procedendo poder-se-á afirmar sem angústias e inquietações - a existência do direito à saúde.

\section{REFERENCIAS}

CHADWICK, E. Reports on the sanitary condition of the laboring population of Great Britain. Edinburgh: University Press, 1965.

COMPARATO, F. K. Direitos humanos e Estado. In: FESTER, A. C. R. (Org.) Direitos humanos e... São Paulo: Brasiliense,1989.

DALLARI, Dalmo de Abreu. Elementos de teoria geral do Estado. 20. ed. São Paulo: Saraiva, 1999.

HABERMAS, J. Droit et démocratie: entre faits et normes. Paris: Gallimar, 1996.

MARQUES, Silvia Badim. "A relação do sistema jurídico e do sistema político na garantia do direito social à assistência farmacêutica: o caso do Estado de São Paulo", apresentada à Faculdade de Saúde Pública da Universidade de São Paulo em agosto de 2005.

NASCIMENTO, P. R.; ZIONI, F. Relaçōes federativas no SUS: autonomia nas relações intergovernamentais da CIB-SP. Revista de Direito Sanitário. São Paulo, ano 3, n. 2, p. 11-33, jul. 2002.

ORGANIZACIÓN Mundial de la Salud. Pautas para establecer politicas farmacéuticas nacionaneles. Ginebra: OMS, 1988.

PLATÃO. A república, IV, 444b-c.

RAUCH, A. Histoire de la santé. Paris: PUF, 1995.

SOBRAVIME O que é o uso racional de medicamentos. São Paulo: SOBRAVIME, 2001.

TEUBNER, G. Le droit. um système autopoiëtique. Paris: PUF, 1993. 